\title{
Crohn's disease activity evaluation based on imaging studies and biomarkers
}

\begin{abstract}
Background and aims: Crohn's disease (CD) is a chronic condition with a variable course. Available grading systems include clinical assessment using CDAI scale, imaging studies and biomarkers. The aim of this study is to determine the suitability of available diagnostic methods, by means of comparison, for predicting the disease activity, based on cost efficiency and sensitivity criteria.

Materials and methods: In this study, we conducted analyses of 37 patients with CD. Crohn's disease was graded as "active" or "inactive" by adopting certain cut off values for every marker.

The main assumption was that methods used to grade CD severity (Endoscopy SESCD scale, MRI enterography: DWI ADC, CRP and Calprotectine) do not give false positive results. In addition none of these methods was considered a reference method. Authors also decided to measure the agreement between the methods by applying the Cohen's Kappa coefficient and compare them to the CDAI method.

Results: Endoscopy shows the highest sensitivity, NPV and accuracy in detecting activity of $\mathrm{CD}$ overall and in each intestine separately. In the case of involvement of both intestines, the sensitivity of endoscopy reached $93.9 \%$ and the accuracy $94.6 \%$, while the sensitivity and accuracy of enterography and calprotectin were $51.5 \%$ vs. $71.9 \%$ and $56.8 \%$ vs. $72.2 \%$, respectively. For the large intestine, the sensitivity and accuracy of endoscopy reached $100.0 \%$. This means that there were no cases when enterography detected the activity of disease and endoscopy did not. For the small intestine, the sensitivity of endoscopy was $55.0 \%$ and accuracy $75.0 \%$, while enterography showed only $66.7 \%$ and $81.1 \%$ respectively. The best agreement (77.1\%), taking into account all pairs of methods, and the only one which proved to be statistically important $(\mathrm{p}=0.005$ ) was between endoscopy and calprotectin regarding the involvement of both small and large intestine. However, the value of Cohen's Kappa suggest that this agreement is rather moderate. The optimal cut- off value for calprotectin was $43.0 \mu \mathrm{g} / \mathrm{g}$ for both techniques (Tangent method and Youden's index). Area under the ROC curve $(\mathrm{AUC}=0.871)$ was large enough to conclude that calprotectin is a statistically significant $(\mathrm{p}<0.001)$ indicator of $\mathrm{CD}$ activity in both small and large intestine.
\end{abstract}

Conclusion: Statistically significant compliance was shown only between colonoscopy and fecal calprotectin.

Keywords: biomarkers, imaging, crohn's disease, CDAI, CRP, MRE, SES-CD, fecal calprotectin
Volume 9 Issue 2 - 2018

\author{
Grażyna Piotrowicz,' Agnieszka Klufczyńska,' \\ Jacek Kowerzanow,' Piotr Banaszkiewicz,' \\ Grażyna Rydzewska ${ }^{2,3}$ \\ 'Department of Gastroenterology, Self-Dependent Health Care \\ Unit of Ministry of Interioir, Gdansk, Poland \\ ${ }^{2}$ Department of Internal Medicine and Gastroenterology with \\ IBD Subdivision, Central Clinical Hospital of the Ministry of the \\ Interior, Poland \\ ${ }^{3}$ Faculty of Health Sciences, Jan Kochanowski University, Poland
}

Correspondence: Grazyna Piotrowicz, Department of Gastroenterology, Self-Dependent Health Care Unit of Ministry of Interioir, str. Kartuska 4/6,80-104 Gdansk, Poland.Tel +48583098343, Fax +48583021782,

Email piotrowicz.grazyna@interia.eu

Received: December 05, 2017 | Published: March 13, 2018

\section{Introduction}

Inflammatory bowel diseases like Crohn's disease or ulcerative colitis represent a group of chronic conditions characterized by periods of flare-ups and remissions. In the Northern Hemisphere, the incidence rate of Crohn's disease amounts to $1-10$ per 100.000 people, whereas the prevalence rate is estimated at $1-0.5$ per 1.000 people. Therefore, Crohn's disease is not considered a rare condition in neither Europe nor North America. ${ }^{1}$

The therapeutic goal of the IBD treatment is not only to achieve a clinical remission, but also to induce mucosal healing, which contributes to a long-term remission. The monitoring of patients with inflammatory bowel diseases should be optimized in such a way as to identify the activity of the disease at its subclinical stage, and consequently modify the treatment, taking into consideration costs. Currently, different methods are used to assess the activity of the disease, including: Crohn's Disease Activity Index (CDAI), inflammatory biomarkers and medical imaging, which shows the severity of inflammatory changes.
Crohn's Disease Activity Index (CDAI) is considered the golden standard for assessing the clinical condition of patients. According to the ECCO guidelines, a CDAI score $<150.0$ points indicates a remission, whereas a CDAI score $>220.0$ points indicates disease exacerbation. ${ }^{2}$ Biomarkers used in laboratory tests include: C-reactive protein (CRP), hemoglobin, leukocytes, thrombocytes, serum iron, ferritin, ceruloplasmin, alpha1-antitripsin, plasminogen, fibrinogen, interleukin 6, salicylic acid and amyloid A. ${ }^{3}$ Fecal biomarkers include: fecal calprotectin (FC), fecal lactoferrin (FL), elastase, myeloperoxidase, metalloproteinase 9 and neoprotein. ${ }^{4}$

CRP, a protein produced by hepatocytes, is not characteristic solely of IBD. The CRP level is elevated in other inflammatory diseases as well., ${ }^{5,6}$ In IBD, the CRP level should be measured along with other markers, such as erythrocytes, hemoglobin and albumins. ${ }^{7}$ In addition, high CRP levels are more often seen in transmural pattern of inflammation (Crohn's disease), rather than in ulcerative colitis. ${ }^{8-10}$

There is a correlation between elevated CRP levels and the clinical activity of $C D,^{7,11,12}$ however in $20.0-25.0 \%$ of patients with severe 
$\mathrm{CD}$, there is no increase in the CRP level due to a single-nucleotide polymorphism in the CRP gene. ${ }^{13}$ The cut-off value for CRP in inflammatory bowel diseases should be $>5.0 \mathrm{mg} / \mathrm{dl}$, which is also related to the activity of the disease in the endoscopic evaluation. ${ }^{14}$ Fecal calprotectin (FC) is an inflammatory protein found in the cytosol of human neutrophils, macrophages and monocytes. ${ }^{15,16}$ When inflammation is present, the FC level is in direct proportion to the migration of neutrophils to the digestive tract. This is the reason for increased levels of FC in case of inflammatory diseases of the digestive tract in general.

Furthermore, it seems that the FC level correlates with histologic results and therefore can serve as a predictor of relapse. ${ }^{17}$ According to a study, the median FC level in patients with relapses was 414.0 $\mu \mathrm{g} / \mathrm{g}$, compared to $96.0 \mu \mathrm{g} / \mathrm{g}$ in patients without a relapse $(\mathrm{p}<0.005)$. However, the FC level of $240.0 \mu \mathrm{g} / \mathrm{g}$ was a predictor of relapse within 12 month period. ${ }^{18}$ Therefore, CRP and FC are recognized markers for assessing the subclinical activity of IBD. CRP is an easy and fast biochemical parameter to measure, however there is a poor correlation with clinical and endoscopic assessments. ${ }^{13} \mathrm{FC}$ is a more expensive, but also more specific parameter of inflammation activity, and has a better correlation with the endoscopic assessment (excluding isolated changes in the small intestine). The FC level below $50.0 \mathrm{mg} / \mathrm{g}$ indicates an inactive process. Different methods of assessing FC may generate different results, varying from $7.8 \%$ to $28.1 \%{ }^{18}$

Consequently, a further observation is required in order to compare FC levels with endoscopic images, due to the fact that in different studies the FC level was measured at different time intervals with reference to colonoscopy, which makes it more difficult to determine the cut-off value of this biomarker. The FC level for isolated changes in the small intestine are lower, and therefore, its predictive value should be lower compared to the large intestine. Thus, if the FC level below $50.0 \mu \mathrm{g} / \mathrm{g}$ indicates a remission, whereas the $\mathrm{FC}$ level above $250.0 \mu \mathrm{g} / \mathrm{g}$ suggests disease activity, one has to question how to interpret other borderline values. ${ }^{19,20}$

Magnetic resonance enterography (MRE), an examination used for visualizing small intestine damage, is an important complementary test to colonoscopy. Along with biochemical endoscopic assessments, MRE is used to diagnose and assess the activity of IBD; nevertheless, ileocolonoscopy with biopsy still remains the first-line diagnostic tool. ${ }^{21-23}$ MRE and CTE (computed tomography enterography) are imaging techniques used to investigate intramural changes and complications of CD. ${ }^{24-26}$

Taking into consideration the onset of $\mathrm{CD}$ in patients, its chronic character, recurrence, frequent involvement of the small intestine and the risk of developing complications, it seems necessary to repeat imaging examinations, especially MRE, in patients with IBD. ${ }^{27-29}$ MRE is recommended by ECCO, not only as a diagnostic tool, but also as a monitoring tool in patients with $\mathrm{CD} \cdot{ }^{22,23}$ It also determines the choice of treatment: conservative or surgical. ${ }^{30,31}$

A comparison study conducted to evaluate the diagnostic value of MRE and ileocolonoscopy in monitoring the response to treatment in patients with CD showed that both methods have a similar degree of reliability when it comes to assessing the healing of changes $(90.0 \%$ vs. $83.0 \%)^{32}$

Colonoscopy is a recommended method for assessing the disease activity in the large intestine and the distal segment of the ileum. Currently, two methods are applied to assess the inflammation:
SES-CD (Simple Endoscopic Score Index) and CDEIS (Crohn's Disease Index of Severity). ${ }^{33}$ Both methods involve the use of video colonoscopy. In the SES-CD system, five bowel segments are examined, and values ranging from 0 to 3 are given to each segment, taking into consideration the following variables: ulcerated surface, size of ulcers, affected surface and narrowings. ${ }^{34}$

The study described in this article was performed to assess and compare methods used for the assessment of inflammation activity in $\mathrm{CD}$, such as: blood and fecal biomarkers, imaging techniques and clinical assessment based on CDAI. The aim of the study was to determine which method is the most accurate and therefore could be used to optimize the monitoring of patients, as well as to modify the currently used methods of treatment.

\section{Material and methods}

\section{Study design}

The study enrolled 37 patients with Crohn's disease hospitalized in the Department of Gastroenterology of the Self-Dependent Health Care Unit of Ministry of Interioir in Gdańsk in 2015-2017 to assess CD activity based on CDAI, blood biomarkers (hemoglobin, thrombocytes, iron, CRP), fecal biomarker (calprotectin) and imaging techniques (ileocolonoscopy and magnetic resonance enterography).

Tests were conducted at a one-week interval between imaging examinations, and other laboratory analyzes were performed at a single stage, 24 hours before colonoscopy. The CDAI calculator take into consideration: sex, weight, height, age, hematocrit, presence of abdominal masses, extra-intestinal complications, anti-diarrhea drug use, number of soft/liquid stools, severity of abdominal pain and patient's general well-being.

Crohn's disease may be active or inactive. The cut-off values were set at the CDAI score $\leq 150.0$ for the inactive disease and at the CDAI score $>150.0$ for the active disease. An immunoturbidymetric method was used to assay serum CRP, which is a test for quantitative determination with high sensitivity, using antibodies coated on latex, against this human acute phase protein. ${ }^{35}$ The cut-off value of $5.0 \mathrm{mg} /$ $\mathrm{dl}$ was set to differentiate between the active disease (above the cutoff level and inactive disease (below the cut-off level).

Fecal calprotectin was measured using the Quantum Blue Calprotectic test for the quantitative measurement of calprotectin level in fecal samples. Stool samples were stored in a refrigerator at $2.0-8.0^{\circ} \mathrm{C}$ and examined within 24 hours, similarly to specimen tubes. Both stool samples and specimen tubes were stored at room temperature of $24.0 \pm 4.0^{\circ} \mathrm{C}$ for 20.0 minutes before the procedure. Next, each stool sample was disrupted and dissolved in an extraction buffer. An automatic pipette was used to collect fecal specimen, which was then inserted into a separate specimen tube and dissolved in the "Chase buffer" in a $1: 15$ ratio $(20.0 \mu 1$ of the specimen $+280.0 \mu 1$ of the buffer). The reader was calibrated to an extended range (30.0$1800.0 \mu \mathrm{g} / \mathrm{g}$ ) and the fecal extract of $60.0 \mu 1$ was loaded onto the loading port of the test cassette. After 12.0 minutes of incubation, the extract was put in the tray. The test cassette was automatically read and the result was displayed on a screen. The cut-off value was set at $100.0 \mu \mathrm{g} / \mathrm{g}$ for disease activity.

In ileocolonoscopy, a SES-CD score was used to assess the disease activity. Five bowel segments were examined and the following criteria were used to assess the severity of the disease: Table 1. 
Table I Simple endoscopic score (SES-CD)

\begin{tabular}{lllll}
\hline Variable & $\mathbf{0}$ & $\mathbf{I}$ & $\mathbf{2}$ & $\mathbf{3}$ \\
\hline Size of ulcers $(\mathrm{cm})$ & None & Aphthous ulcers & Large ulcers & Very large ulcers \\
& & $($ diameter $0.1-0.5)$ & $($ diameter $0.5-2)$ & $($ diameter $>2)$ \\
Ulcerated surface & None & $<10 \%$ & $10-30 \%$ & $>30 \%$ \\
Affected surface & Unaffected segment & $<50 \%$ & $50-75 \%$ & $>75 \%$ \\
Presence of narrowings & None & $\begin{array}{l}\text { Single, can be } \\
\text { passed }\end{array}$ & Multiple, can be passed & Cannot be passed \\
\hline
\end{tabular}

SES-CD $=$ Sum of all variables for the 5 bowel segments. Values are given to each variable for every examined bowel segment ${ }^{34}$

Adding the scores from all five segments assessed the disease activity. The final score was interpreted in the following manner:

$\leq 2.0$ : inactive $\mathrm{CD}$

3.0-6.0: mild CD

7.0-15.0: moderate CD

>16.0: severe CD

For the purposes of this study, the score $\leq 2.0$ points was considered indicative of an inactive inflammation process. Scores above 2.0 points, on the other hand, were indicative of an active inflammation process. In MRE, the disease activity was assessed as active or inactive (by assessing the location of changes and the severity of the inflammation process) in the small and large intestine, based on the following examination protocol: before the examination, a patient is asked to drink approx. 1.51 of $3.0 \%$ mannitol solution over 60 minutes. During the examination, a contrast agent is administered (ProHance or Gadovist), and the following sequences are analyzed according to the protocol:

\section{i. T2 haste cor}

Slice $3.5 \mathrm{~mm}$ gap $0.0 \mathrm{~mm}$

TR $1200.0 \mathrm{~ms}$ TE $100.0 \mathrm{~ms}$

Matrix 288.0x384.0

\section{ii. T2 haste stir cor}

Slice $4.0 \mathrm{~mm}$ gap $0.0 \mathrm{~mm}$

TR $1200.0 \mathrm{~ms}$ TE $100.0 \mathrm{~ms}$ TI $180.0 \mathrm{~ms}$

Matrix 288.0x384.0

iii. T2 trufi cor

Slice $4.0 \mathrm{~mm}$ gap $0.0 \mathrm{~mm}$

TR $3.51 \mathrm{~ms}$ TE $1.45 \mathrm{~ms}$

Matrix 167.0x256.0

\section{iv. DWI cor}

Slice $5.0 \mathrm{~mm}$ gap $0.0 \mathrm{~mm}$

TR $6400.0 \mathrm{~ms}$ TE $65.0 \mathrm{~ms}$

Matrix $160.0 \times 160.0$

$\mathrm{b}=0,50,500,800$

v. T2 haste tra

Slice $4.0 \mathrm{~mm}$ gap $0.0 \mathrm{~mm}$
TR $1200.0 \mathrm{~ms}$ TE $102.0 \mathrm{~ms}$

Matrix 260.0x320.0

\section{vi. T1 flash tra}

Slice $4.0 \mathrm{~mm}$ gap $0.8 \mathrm{~mm}$

TR $189.0 \mathrm{~ms}$ TE $4.93 \mathrm{~ms}$

Matrix 203.0x320.0

\section{vii. $\mathrm{T1}$ vibe fs cor dynamika $\mathrm{CM}$}

Slice $3.0 \mathrm{~mm}$ gap $0.6 \mathrm{~mm}$

TR $4.36 \mathrm{~ms}$ TE $1.92 \mathrm{~ms}$

Matrix 183.0x288.0

Dynamik - 8.0

\section{T1 flash fs tra}

Slice $4.0 \mathrm{~mm}$ gap $0.8 \mathrm{~mm}$

TR $145.0 \mathrm{~ms}$ TE $2.38 \mathrm{~ms}$

matrix $167.0 \times 256.0$

\section{Statistical analysis}

All data were compared by means of statistical analysis to determine the correlation between them and, at the same time, to identify the usefulness of particular markers of disease activity with reference to their sensitivity, specificity, as well as reliability, which has an impact on retesting and economic aspects of different tests. The main assumption of the analysis was that methods used to detect Crohn's disease activity (CDAI, Endoscopy, Enterography and Calprotectine) do not give false positive results. Moreover, none of these methods was considered a reference method. The true positive conditions were defined when either of the methods yielded a positive result. In other words, true negative conditions were specified when an investigation by all three methods brought a negative result. This implied that specificity and PPV (positive predictive value) were equal to $100.0 \%$. Therefore, the comparison of methods presented in the article was based on sensitivity, NPV (negative predictive value) and accuracy. The authors also decided to measure the agreement between all methods based on the Cohen's Kappa coefficient and compare them to the CDAI based method.

Additionally, an optimal cut-off value was set, for calprotectin, based on the ROC curve, with the use of two techniques: tangent method and Youden index. Finally, all comparative analyses were performed separately for the small and large intestine, when possible.

The level of significance was set at $\alpha=0.05$ and all statistical 
analyses were performed using Statistica version 12.5.

The analysis was based on the following assumptions:

a. There is no golden standard when it comes to detecting the disease activity in the small and large intestine,

b. Methods based on endoscopy and enterography have a positive predictive value $(\mathrm{PPV}=100.0 \%)$, which means that if a patient is diagnosed with an active disease, the diagnosis is $100.0 \%$ certain there are no false positive results (Specificity $=100.0 \%$ ).

A variable was defined as, "Reality," which showed whether the disease is active, i.e. whether any of the two imaging techniques (Endoscopy or Enterography) revealed the activity of the disease.

It was assumed that:

a. CDAI score $>150.0$ points indicates disease activity,

b. SES-CD score $>2.0$ points indicates disease activity,

c. CRP level $>5.0 \mathrm{mg} / \mathrm{dl}$ indicates disease activity,

d. Calprotectin level $>100.0 \mu \mathrm{g} / \mathrm{g}$ indicates disease activity.

\section{Results}

\section{Approach no I}

When the disease activity is assessed without dividing the intestine into segments - i.e. in the small and large intestine as a whole - it means that the disease is considered active, if it occurs in any of the two bowel segments (Table 2).

Table 2 Endoscopy

\begin{tabular}{|c|c|c|c|}
\hline \multirow{2}{*}{\multicolumn{2}{|c|}{ Observed frequency }} & \multicolumn{2}{|l|}{ Reality } \\
\hline & & Active & Inactive \\
\hline \multirow{3}{*}{ Ileocolonoscopy } & Active & 31 & 0 \\
\hline & Inactive & 2 & 4 \\
\hline & Total & 33 & 4 \\
\hline
\end{tabular}

Sensitivity $=93.9 \%$, Specificity $=100.0 \%, P P V=100.0 \%, N P V=66.7 \%, A C C=94.6 \%$

This means that in $93.9 \%$ of patients, the disease activity was detected correctly

$100.0 \%$ of patients who have no disease activity have been detected by endoscopy

The patient diagnosed with the disease activity has it on $100.0 \%$

The patient diagnosed with inactivity does not have $66.7 \%$

The diagnosis for the patient (regardless of the result) by the endoscopy is accurate in $94.6 \%$

Table 3 : In $51.5 \%$ of patients, the disease activity was correctly detected

$100.0 \%$ of patients who have no disease activity were detected by enterography

The patient diagnosed with the disease activity has it on $100.0 \%$

The patient diagnosed with inactivity does not have $20.0 \%$

Diagnosis for the patient (regardless of the result) adopted according to the MRE study is accurate in $56.8 \%$

Table 4 : In $71.9 \%$ of patients, the disease activity was correctly detected

\section{Table 3 MRI}

\begin{tabular}{llll}
\hline \multirow{2}{*}{ Observed frequency } & \multicolumn{2}{l}{ Reality } \\
\cline { 3 - 4 } & Active & Inactive \\
\hline \multirow{3}{*}{ MR Enterography } & 17 & 0 \\
& Inactive & 16 & 4 \\
& Total & 33 & 4
\end{tabular}

Sensitivity $=51.5 \%$, Specificity $=100.0 \%, P P V=100.0 \%, N P V=20.0 \%, A C C=56.8 \%$

Table 4 Calprotectin

\begin{tabular}{|c|c|c|c|}
\hline \multirow{2}{*}{\multicolumn{2}{|c|}{ Observed frequency }} & \multicolumn{2}{|l|}{ Reality } \\
\hline & & Active & Inactive \\
\hline \multirow{3}{*}{ Fecal calprotectin } & Active & 24 & I \\
\hline & Inactive & 9 & 3 \\
\hline & Total & 33 & 4 \\
\hline
\end{tabular}

Sensitivity $=71.9 \%$, Specificity $=75.0 \%, P P V=95.8 \%, N P V=25.0 \%, A C C=72.2 \%$

$75.0 \%$ of patients who have no disease activity have been detected by calprotectin

The patient diagnosed with the disease activity has $95.8 \%$

A patient diagnosed with inactivity does not have $25.0 \%$

The diagnosis for the patient (regardless of the result) by calprotectin is accurate in $75.0 \%$

Table 5: Among patients with active disease, $58.8 \%$ of cases were detected correctly.

\section{Table 5 CRP}

\begin{tabular}{llll}
\hline \multirow{2}{*}{ Observed frequency } & \multicolumn{2}{l}{$\begin{array}{l}\text { Reality (for both } \\
\text { intestines) }\end{array}$} \\
\cline { 3 - 4 } & Active & Inactive \\
\hline \multirow{3}{*}{ CRP } & Active & 20 & 0 \\
& Inactive & 14 & 3 \\
& Total & 34 & 3
\end{tabular}

Sensitivity $=58.8 \%$, Specificity $=100.0 \%, P P V=100.0 \%, N P V=22.2 \%, A C C=63.2 \%$

$100.0 \%$ of patients who have no disease activity were supported by CRP

The patient diagnosed with the disease activity has it on $100.0 \%$

The patient diagnosed with lack of activity does not have $22.2 \%$

The diagnosis for a patient based on the threshold value of CRP is accurate in $63.2 \%$

Table 5: In $76.5 \%$ of patients, the disease activity was correctly detected

$25.0 \%$ of patients who have no disease activity have been determined by CDAI 
The patient diagnosed with the disease activity has it at $89.7 \%$

A patient diagnosed with inactivity does not have $11.0 \%$

The diagnosis for the patient (regardless of the result) by CDAI is accurate in $71.1 \%$

Table 6 CDAI

\begin{tabular}{llll}
\hline \multirow{2}{*}{ Observed frequency } & \multicolumn{2}{l}{ Reality } \\
\cline { 3 - 4 } & Active & Inactive \\
\hline & Active & 25 & 3 \\
CDAl & Inactive & 8 & 1 \\
& Total & 33 & 4
\end{tabular}

Sensitivity $=76.5 \%$, Specificity $=25.0 \%$, PPV=89.7\%, NPV= I I. $1 \%$, ACC $=71.1 \%$

\section{Approach no 2}

If we treat the assessment of disease activity separately, i.e. we will analyze these exponents separately for changes in the small intestine and separately for changes in the large intestine, the statistical evaluation of the diagnostic methods used will be as follows:

\section{Small intestine}

Table 7: In $55.0 \%$ of patients, the activity of the disease in the small intestine was correctly detected.

Table 7 Endoscopy

\begin{tabular}{llll}
\hline \multirow{2}{*}{ Observed frequency } & \multicolumn{2}{l}{ Reality } \\
\cline { 3 - 4 } & Active & Inactive \\
\hline \multirow{2}{*}{ Endoscopy } & Active & 12 & 0 \\
\multirow{2}{*}{ (small intestine) } & Inactive & 9 & 16 \\
& Total & 21 & 16
\end{tabular}

Sensitivity $=55.0 \%$, Specificity $=100.0 \%, P P V=100.0 \%, N P V=64.0 \%, A C C=75.0 \%$

$100.0 \%$ of patients who have no disease activity have been detected by endoscopy

The patient diagnosed with the disease activity has it on $100.0 \%$

The patient diagnosed with inactivity does not have $64.0 \%$

Diagnosis for the patient (regardless of the result) through the use of endoscopy is accurate in $75.0 \%$.

Table 8: In $66.7 \%$ of patients, the activity of the disease in the small intestine was correctly detected.

Table 8 MRI

\begin{tabular}{llll}
\hline \multirow{2}{*}{ Observed frequency } & \multicolumn{2}{c}{ Reality } \\
\cline { 3 - 4 } & & Active & Inactive \\
\hline \multirow{2}{*}{ MR Enterography } & Active & 14 & 0 \\
(small intestine) & Inactive & 7 & 16 \\
& Total & 21 & 16 \\
\hline
\end{tabular}

Sensitivity $=66.7 \%$, Specificity $=100.0 \%$, PPV $=100.0 \%, \quad \mathrm{NPV}=69.6 \%$, ACC $=81.1 \%$,
$100.0 \%$ of patients who have no disease activity were detected by enterography

The patient diagnosed with the disease activity has it on $100.0 \%$

A patient diagnosed with inactivity does not have $69.6 \%$

Diagnosis for the patient (regardless of the outcome) evaluated in the MRI enterografis is accurate in $81.1 \%$.

Table 9: Among patients with active disease, $66.7 \%$ of cases were detected correctly.

\section{Table 9 CRP}

\begin{tabular}{llll}
\hline \multirow{2}{*}{ Observed frequency } & \multicolumn{2}{l}{ Reality } \\
\cline { 3 - 4 } & Active & Inactive \\
\hline \multirow{2}{*}{ CRP } & Active & 14 & 5 \\
\multirow{2}{*}{ (small intestine) } & Inactive & 7 & 11 \\
& Total & 21 & 16 \\
\hline
\end{tabular}

Sensitivity $=66.7 \%$, Specificity $=68.8 \%, P P V=73.7 \%, N P V=61.1 \%, A C C=67.6 \%$,

$68.8 \%$ of patients who have no disease activity were supported by CRP

The patient diagnosed with the disease activity has it on $73.7 \%$

A patient diagnosed with a lack of activity does not have it on $61.1 \%$

The diagnosis for the patient based on the threshold value of CRP is accurate in $67.6 \%$

\section{Large intestine}

Table 10: In $96.4 \%$ of patients, the disease activity in the large intestine was correctly detected

Table 10 Endoscopy

\begin{tabular}{llll}
\hline \multirow{2}{*}{ Observed frequency } & \multicolumn{2}{l}{ Reality } \\
\cline { 3 - 4 } & & Active & Inactive \\
\hline \multirow{2}{*}{ Endoscopy } & Active & 27 & 0 \\
\multirow{2}{*}{ (large intestine) } & Inactive & 1 & 9 \\
& Total & 28 & 9 \\
\hline
\end{tabular}

Sensitivity $=96.4 \%$, Specificity $=100.0 \%$, PPV $=100.0 \%, N P V=90.0 \%, A C C=97.3 \%$

$100.0 \%$ of patients who have no disease activity were detected in the endoscopic examination - colonoscopy

The patient diagnosed with the disease activity has it on $100.0 \%$

The patient diagnosed with inactivity does not have $90.0 \%$

Diagnosis for a patient (regardless of the result) after a colonoscopy is accurate in $97.3 \%$.

Table 11: In case of $33.3 \%$ of patients, the disease activity in the area of large intestine was correctly detected

$100.0 \%$ of patients in whom no disease activity was detected have MR enterographies

The patient diagnosed with the disease activity has it on $100.0 \%$ 
A patient diagnosed with inactivity does not have $33.3 \%$

Table II MRI

\begin{tabular}{llll}
\hline \multirow{2}{*}{ Observed frequency } & & \multicolumn{2}{l}{ Reality } \\
\cline { 3 - 4 } & & Active & Inactive \\
\hline MR Enterography & Active & 9 & 0 \\
\multirow{2}{*}{ (large intestine) } & Inactive & 19 & 9 \\
& Total & 28 & 9 \\
\hline
\end{tabular}

Sensitivity $=33.3 \%$, Specificity $=100.0 \%, P P V=100.0 \%, N P V=33.3 \%, A C C=50.0 \%$

Diagnosis for the patient (regardless of the result) pasted with the use of enterography MR is accurate in $50.0 \%$.

Table 12: Among patients with active disease, $64.3 \%$ of cases were detected correctly.

Table 12 CRP

\begin{tabular}{llll}
\hline \multirow{2}{*}{ Observed frequency } & \multicolumn{2}{l}{ Reality } \\
\cline { 3 - 4 } & Active & Inactive \\
\hline CRP & Active & 18 & $\mathrm{I}$ \\
(large & Inactive & 10 & 8 \\
intestine) & Total & 28 & 9 \\
\hline
\end{tabular}

Sensitivity $=64.3 \%$, Specificity $=88.9 \%$, PPV=94.7\%, NPV= $44.4 \%, A C C=70.3 \%$

Table 13 Agreement of methods
$88.9 \%$ of patients who have no disease activity were supported by CRP

The patient diagnosed with the disease activity has $94.7 \%$

A patient diagnosed with inactivity does not have $44.4 \%$

The diagnosis for a patient based on the CRP threshold is accurate in $70.3 \%$

\section{Agreement of methods}

The agreement of methods was assessed using an unadjusted coefficient of agreement and the Cohen's Kappa coefficient (Table 13). A statistically significant agreement of methods was identified in the case of Endoscopy and Calprotectin, as well as CRP values and CDAI values. There was a correlation between CRP and Calprotectin, CRP and Enterography of the small intestine and CRP and colonoscopy of the large intestine.

\section{Calprotectin cut-off values}

Calprotectin shows a high degree of effectiveness in the detection of $\mathrm{CD}$ activity in the large intestine and the bowel in general. However, the level of this biomarker should not be used for assessment of the disease activity solely within the small intestine (Figure 1) (Table 14).

According to the Youden Index, the cut-off value of $100.0 \mu \mathrm{g} / \mathrm{g}$ (sensitivity $=88.9 \%$, specificity $=87.5 \%$ ) and $43.0 \mu \mathrm{g} / \mathrm{g}$ (sensitivity $=93.8 \%$, specificity $=75.0 \%$ ) should be used for the large intestine and a full-scope detection respectively.

\begin{tabular}{lllll}
\hline Compared methods & Coefficient of & $\begin{array}{l}\text { Cohen's } \\
\text { Kappa }\end{array}$ & p-value \\
\hline Ileocolonoscopy & MR Enterography & $50.00 \%$ & 0.069 & 0.549 \\
Ileocolonoscopy & Fecal calprotectin & $77.10 \%$ & 0.424 & 0.005 \\
MR Enterography & Fecal calprotectin & $54.30 \%$ & 0.094 & 0.555 \\
CDAI & Ileocolonoscopy & $52.60 \%$ & -0.305 & 0.179 \\
CDAI & MR Enterography & $57.90 \%$ & 0.283 & 0.078 \\
CDAI & Fecal calprotectin & $52.90 \%$ & 0.029 & 0.893 \\
Endoscopy (small & MR Enterography (small & $57.90 \%$ & 0.038 & 0.865 \\
intestine) & intestine) & $47.40 \%$ & 0.159 & 0.2 \\
Endoscopy & MR Enterography & & & \\
(large intestine) & (large intestine) & $67.60 \%$ & 0.339 & 0.006 \\
CRP & Ileocolonoscopy & $67.60 \%$ & 0.353 & 0.031 \\
CRP & MR Enterography & $72.20 \%$ & 0.423 & 0.009 \\
CRP & Fecal Calprotectin & $76.30 \%$ & 0.513 & $<0.001$ \\
CRP & CDAl & $62.20 \%$ & 0.251 & 0.091 \\
CRP & $\begin{array}{l}\text { Endoscopy (small } \\
\text { intestine) }\end{array}$ & & & \\
\hline & & & & \\
\hline
\end{tabular}


Table I4 Calprotectin values

\begin{tabular}{|c|c|c|c|c|}
\hline \multirow[t]{2}{*}{ Scope } & \multicolumn{2}{|c|}{$\begin{array}{l}\text { Cut-off values } \\
\text { according to }\end{array}$} & \multirow[t]{2}{*}{ AUC } & \multirow[t]{2}{*}{ p-value } \\
\hline & $\begin{array}{l}\text { Tangent } \\
\text { method }\end{array}$ & $\begin{array}{l}\text { Youden } \\
\text { Index }\end{array}$ & & \\
\hline $\begin{array}{l}\text { Small and } \\
\text { large intestine }\end{array}$ & 43 & 43 & 0.871 & $\mathrm{p}<0.00 \mathrm{I}$ \\
\hline Small intestine & 61 & 61 & 0.439 & 0.549 \\
\hline Large intestine & 63 & 100 & 0.944 & $p<0.001$ \\
\hline
\end{tabular}

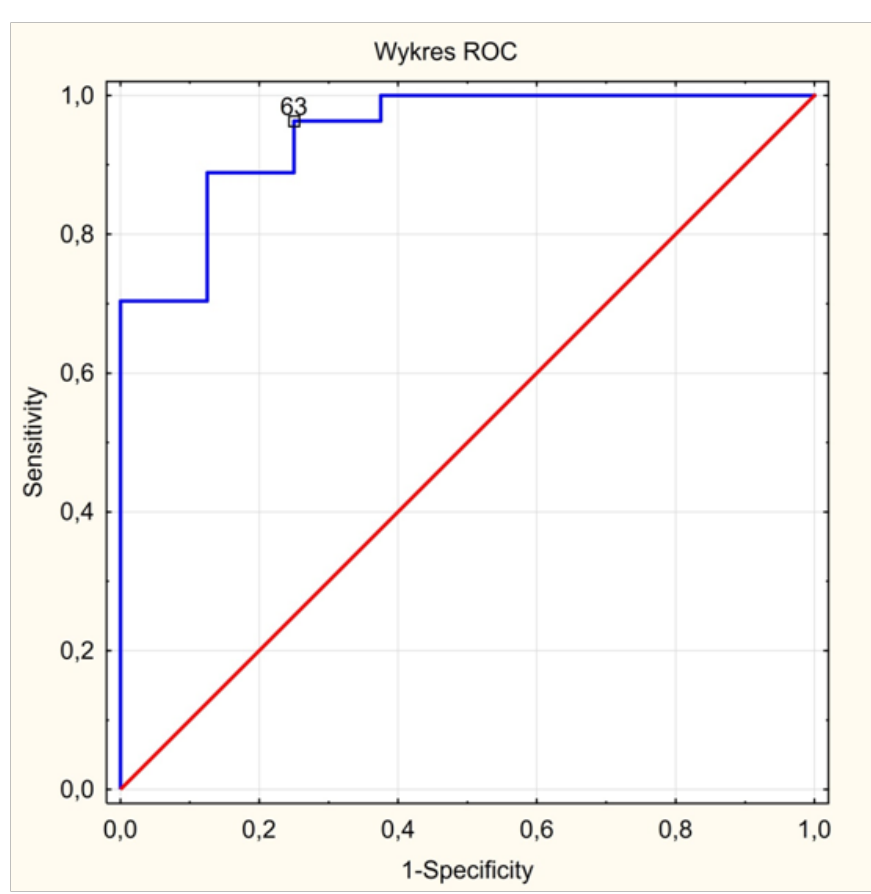

Figure I ROC curve for Calprotectin.

\section{Discussion}

Recently, the clinical management of patient with IBD has evolved, with the main aim now being not only a clinical remission, but also mucosal healing.

Therefore, it is necessary to monitor the disease activity in order to detect it at its early subclinical stage, as well as taking the cost into account.

In this study, the following testing methods were assessed:

Clinical evaluation of CDAI disease activity,

Biomarkers: fecal calprotectin and serum CRP,

Imaging examinations: ileocolonoscopy, MR enterography.

Since $\mathrm{CD}$ is a disease of the gastrointestinal system, the effectiveness of these tests was examined both comprehensively (in the two bowels) and in the small or large intestine separately, depending on the disease activity. Diagnostic tests were assessed in terms of their sensitivity and specificity, and in addition they were also compared to each other in order to specify which test is the most effective in quantitating $\mathrm{CD}$ activity, taking into consideration the fact that $20.0 \%$ of patients experience early relapses.
The current golden standard in assessing the disease activity is the CDAI system.

According to the ECCO consensus, a clinical remission can be diagnosed when the CDAI score is below 150.0 points. The disease is active when a patient scores more than 220.0 points. ${ }^{2}$ However, this index is often criticized for being too subjective.

In our study, the sensitivity of this method (with a cut-off value of 150.0 points) was $76.5 \%$, whereas the specificity - a mere $25.0 \%$. The predictive positive value (PPV) was $89.7 \%$ and the predictive negative value (PNV) was $11.1 \%$. The accuracy of this method (ACC), which reflects the correct diagnosis of a patient regardless of the findings, was $71.1 \%$. This can be set in comparison to a study where CDAI was set against mucosal healing, defined as the lack of ulceration, and where the cut-off value for the disease activity was 150.0 points, PPV amounted to $65.0 \%$ and NPV - to $53.0 \%$. Another parameter that was investigated was CPR, which is a relatively cheap and quick method of assessing CD activity. The activity of the disease correlated with the CPR level, ${ }^{7,11,12}$ but it is important to have in mind that in 20.0$25.0 \%$ of patients with severe CD, there is no CRP elevation.

In our study, the cut-off value for the process of inflammation was set at the CRP level of $5.0 \mathrm{mg} / \mathrm{dl}$. It was demonstrated that when assessing this parameter in patients with changes limited to the small intestine, the sensitivity and specificity amounted to $66.7 \%$ and $68.8 \%$ respectively. PPV and NPV were at the level of $73.3 \%$ and $67.6 \%$ respectively, whereas the accuracy was estimated at $67.6 \%$. In the case of changes within the large intestine, the sensitivity and specificity of this method was estimated at $64.3 \%$ and $88.0 \%$ respectively, with PPV and NPV amounting to $94.7 \%$ and $44.4 \%$ respectively. The accuracy of the method was $70.3 \%$. Without differentiating the range of inflammatory changes, the sensitivity of the method was calculated at $58.8 \%$ with a $100.0 \%$ specificity, whereas PPV and NPV stood at $100.0 \%$ and $22.2 \%$ respectively. In this case, the accuracy was estimated at $33.2 \%$.

In a study by Solem et al., it was shown that CPR $<5.0 \mathrm{mg} /$ $\mathrm{dl}$ with a normal endoscopic appearance of the intestinal mucosa is found in $75.0 \%$ of cases, and the elevated CPR level correlated with inflammatory changes. However, another study (36) showed that isolated changes in the ileum correspond with high CPR values. Mosli et al. ${ }^{14}$ conducted a meta-analysis of 19 studies $(n=2499$ patients with IBD), in which the CRP level was compared with the endoscopic appearance of the mucosa. The sensitivity and specificity of this parameter was calculated at $49 \%$ and $92 \%$ respectively, and it was suggested that CPR $>5.0 \mathrm{mg} / \mathrm{dl}$ may indicate an endoscopic inflammatory activity.

Another biomarker, fecal calprotectin (FC), is in proportion to the migration of neutrophils to the digestive tract during an ongoing process of inflammation. ${ }^{5,6,36}$ Besides, FC seems to correlate with the endoscopic and histologic appearance of the mucosa and may be used as a predictor of relapse. ${ }^{5,17}$

In our study, the sensitivity and specificity of fecal calprotectin was calculated at $71.9 \%$ and $75.0 \%$, with PPV and NPV of $95.8 \%$ and $25.0 \%$ respectively. The accuracy (ACC) of this method was estimated at $72.2 \%$. The cut-off value of calprotectin was also determined, depending on the disease activity, which was $43.0 \mu \mathrm{g} / \mathrm{g}$ for the small intestine and $100.0 \mu \mathrm{g} / \mathrm{g}$ for the large intestine $(\mathrm{p}<0.0001)$. The area under the curve (ROC AUC) was 0.87 without differentiating the range of changes and 0.944 for the $\mathrm{FC}$ value of $100.0 \mu \mathrm{g} / \mathrm{g}$ in the case of the large intestine. 
In a study by Mosli et al., ${ }^{14}$ the FC biomarker demonstrated a higher sensitivity in determining the disease activity than CRP. The sensitivity and specificity of this biomarker in CD were $87.0 \%$ and $67.0 \%$ respectively, with a cut-off value of $50.0 \mu \mathrm{g} / \mathrm{g}$. In a study by D'Haens et al., ${ }^{34}$ the greatest ROC AUC was found by the cut-off value of $250.0 \mu \mathrm{g} / \mathrm{g}$, which correlated with an endoscopic remission (CDEIS $<3.0$ points). The sensitivity and specificity were calculated at $94.1 \%$ and $62.2 \%{ }^{38,39}$ The study by Rostek et al. ${ }^{40}$ showed that the FC level $<50.0 \mu \mathrm{g} / \mathrm{g}$ correlates with a full remission on ileocolonoscopy.

The FC sensitivity and specificity was also assessed in relation to changes found during capsule endoscopy. However, the correlation was rather low $-59.0 \%$ and $71.0 \%$ respectively. ${ }^{41} \mathrm{FC}$ values for changes in the small intestine were lower than for changes in the large intestine, but there was a correlation between FC an SES-CD $(\mathrm{p}<0.0001),{ }^{42}$ similarly to a study by Schopter et al., ${ }^{43}$ where this correlation occurred between the distal segment of the ileum and the FC level. ${ }^{43}$ The analysis we conducted also showed a difference in the $\mathrm{FC}$ value for the activity of the inflammatory process in the small intestine and large intestine, with simultaneous correlation of the endoscopic image with the value of this biomarker. In our study, FC the cut-off value used for the inflammation activity was $43.0 \mu \mathrm{g} / \mathrm{g}$ for $\mathrm{CD}$ (ACU 0.87) and $100.0 \mu \mathrm{g} / \mathrm{g}$ in the case of changes limited only to the large intestine (ACU 0.944).

When it comes to the level of FC that predisposes patients to an endoscopic remission, the value varies from study to study. In one study, the sensitivity and specificity of the test was $94.0 \%$ and $62.0 \%$ respectively, with a predicting value of $250.0 \mu \mathrm{g} / \mathrm{g} .{ }^{13}$ In another study, in which the predicting value was set at $200.0 \mu \mathrm{g} / \mathrm{g}$, the sensitivity and specificity was calculated at $70.0 \%$ and $92.0 \%$ respectively. ${ }^{44}$ Yet another study, in which the predicting value was $70.0 \mu \mathrm{g} / \mathrm{g}$, showed that the sensitivity and specificity in examining the process of inflammation during an endoscopic examination amounted to $86.0 \%$ and $72.0 \%$ respectively. ${ }^{45}$

Currently, the cut-off level of $50.0 \mu \mathrm{g}$ is considered an indicator of remission, while the value of $250.0 \mu \mathrm{g}$ is an indicator of the inflammation activity. ${ }^{20}$ Other biochemical parameters, such as complete blood count (hemoglobin, platelets) and iron level, did not correlate with the disease activity, and therefore were not included in the analysis.

In imaging examinations, the usefulness of such techniques as ileocolonoscopy or MR enterography was analyzed. The most sensitive and specific method of assessing the activity of inflammation is ileocolonoscopy. Its limitation, however, is the scope of the examination since it only reaches the distal segment of the ileum. A dedicated scoring system for Crohn's disease, SES-CD, was introduced, so that ileocolonoscopy, as a method of assessing CD activity, could be reproducible and comparable. SES-CD is a scoring system based on a 0-3 scale, in which several variables are analyzed with reference to 5 bowel segments: ulceration, size of ulcers, affected surface of the intestine and presence of stenosis. ${ }^{34}$

In our study, SES-CD was used to assess the inflammation activity during ileocolonoscopy, with cut-off values $<2.0$ points - as an indicator of the disease inactivity - and $>2.0$ points - as an indicator of the disease activity. The sensitivity of this method was calculated at $93.6 \%$, whereas the specificity - at $100.0 \%$. PPV and NPV were $100.0 \%$ and $66.7 \%$ respectively. The accuracy was estimated at $94.6 \%$. When using this method for the distal segment of the ileum, the sensitivity and specificity were $55.0 \%$ and $100.0 \%$ respectively, whereas PPV and NPV $-100.0 \%$ and $64.0 \%$. The accuracy of the method in this case was $75.0 \%$. Obviously, the values are different for the large intestine, where the sensitivity and specificity amounted to $96.4 \%$ and $100.0 \%$ respectively, with PPV and NPV of $100.0 \%$ and $90.0 \%$. The accuracy was calculated at $97.3 \%$. Thus, colonoscopy remains the gold standard when diagnosing IBD. ${ }^{46}$

When assessing the disease activity using a different imaging technique, i.e. MR enterography, the sensitivity of this diagnostic tool was $51.5 \%$, whereas the specificity $-100.0 \%$. PPV and NPV were $100.0 \%$ and $20.0 \%$ respectively. The accuracy stood at $56.8 \%$. The sensitivity and specificity of MRE was slightly better for the small intestine: the values were $66.7 \%$ and $100.0 \%$ respectively, with PPV and NPV of $100.0 \%$ and $69.6 \%$. The accuracy was $81.1 \%$. For the large intestine, on the other hand, the sensitivity and specificity were significantly lower: $33.3 \%$ and $100.0 \%$ respectively, with PPV and NPV of $100.0 \%$ and $33.3 \%$. The accuracy of this method for the large intestine was calculated at $50.0 \%$.

Generally, it is thought that MRE, used as a tool for assessing CD activity, shows an average sensitivity and high specificity within the large intestine. ${ }^{47}$ In a study by Maccioni et al. ${ }^{48}$ the sensitivity and specificity were calculated at $100.0 \%$ in the ileum. In other studies, where CTE and MRE were compared, the values stood at $89.0 \%$ vs. $83.0 \%$ for the sensitivity and $80.0 \%$ vs. $100.0 \%$ for the specificity. ${ }^{47}$ It seems that MRE is a more sensitive diagnostic tool when detecting complications of the disease, such as fistulae or stenosis. ${ }^{49}$

All diagnostic tools analyzed above were also compared to each other, using a non-adjusted coefficient of agreement and the Cohen's Kappa coefficient. The comparison showed a strong correlation between an endoscopic examination - colonoscopy - and fecal calprotectin. In our study, the endoscopic accuracy was calculated at $77.1 \%$, with a FC cut-off point of $43.0 \mu \mathrm{g} / \mathrm{g}$. If the process was in the large intestine, the cut off point for calprotectin was $100.0 \mu \mathrm{g} / \mathrm{g}$ in $96.4 \%$ of cases. Similarly to other examinations, ${ }^{50}$ where the accuracy of detecting an active inflammation process using endoscopy was $87.0 \%$ for the $\mathrm{FC}$ level of $70.0 \mu \mathrm{g} / \mathrm{g}$. This once again emphasizes that applying fecal calprotectin as a biomarker is an effective method of monitoring the inflammation process and may be used to optimize the therapeutic process.

\section{Conclusion}

a. By analyzing diagnostic methods used to assess the disease activity, both within the small intestine (the distal segment of the ileum) and the large intestine, it was found that Endoscopy is the most accurate diagnostic tool, followed by Fecal calprotectin. The least sensitive methods include: MR Enterography and CDAI.

b. A statistically significant agreement between Endoscopy and Fecal calprotectin was demonstrated.

The cut-off value of FC (taking into account both the small intestine and the large intestine), in correlation with endoscopic findings indicative of the disease activity, was $43.0 \mu \mathrm{g} / \mathrm{g}$.

The cut-off value of FC, in correlation with endoscopic findings indicative of the disease activity, was $100.0 \mu \mathrm{g} / \mathrm{g}$ for the large intestine.

C-reactive protein (CRP) shows a statistical significance with CDAI and it correlated with the endoscopic appearance of the large intestine, MRE of the small intestine and the fecal calprotectin level. 
By assessing the inflammation activity for the small and large intestine separately, it was found that MRE is a slightly better diagnostic tool in the case of the small intestine, whereas ileocolonoscopy is a preferred method for examining the large intestine.

\section{Funding}

No funding was received for this study

\section{Conflict of Interest}

The author declares no conflict of interest.

\section{Acknowledgements}

Guarantor of the article: GR. Author contributions: GP, GP, study concept, design, drafting of the manuscript and descriptive analysis; GP, AK, JK, PB. All authors read and approved the final manuscript, including the authorship list.

\section{References}

1. Bartnik W, Szczeklik A. Choroba Leśniowskiego i Crohna. Choroby wewnętrzne. Stan wiedzy na 2010 rok. Kraków: Medycyna Praktyczna; 2010;880-6.

2. Stange EF, Travis SPL, Vermeire S, et al. W Reinisch European evidence based consensus on the diagnosis and management of Crohn's disease definitions and diagnosis ECCO Consensus. Gut. 2006;55 Suppl 1:1-15

3. Sands BE. Biomarkers on Inflammation in Inflammmatory Bowe Disease. Gastroenterology.2015;149(5):1275-85.

4. Wu F, Guo NJ, Tian H, et al. Peripheral blood micro Rnas distinguish active ulcerative colitis and Crohn's disease. Inflamm Bowel Dis. 2011;17(1):241-250

5. Tilett WS, Francis T. Serological reactions in pneumonia with a nonprotein somatic fraction of pneumococcus. J Exp Med. 1930;52(4):561571.

6. Vermeire S, Van Assche G, Rutgeerts P. Laboratory markers in IBD: useful, magic, or unnecessary toys? Gut. 2006;55(3):426-431.

7. Solem CA, Loftus EV, tremaine WJ, etal. Correlation ofC-reactivebprotein with clinical, endoscopic, histologic, and radiographic activity in inflammatory bowel disease. Inflamm Bowel Dis. 2005;11(8):707-712.

8. Vermeire S, Van Assche G, Rutgeerts P. The role of C-reactive protein as an inflammatory marker in gastrointestinal diseases. Nat Clin Pract Gastroenterol Hepatol. 2005;2(12):580-586.

9. Saverymuttu SH, Hadgson HJ, Chadwick VS, et al. Differing acute phase responses in Crohn's disease and ulcerative colitis. Gut. 1986;27(7):809813.

10. Talstad I, Gjone E. The disease activity of ulcerative colitis and Crohn's disease. Scand J Gastroenterol. 1976;11(4):403-408.

11. Karoui S, Ouerdiane S, Serghiani M, et al. Correlation between levels of C- reactive protein and clinical activity in Crohn's disease. Dig liver dis. 2007;39(11):1006-1010

12. Tilakaratne S, Lemberg DA, Leach ST, et al. C-reactive protein and disease activity in children with Crohn's disease. Dig Dis sci. 2010;55(1):131-136

13. Jones J, Loftus EV, Panaccione R, et al. Relationships betweene disease activity and serum and fecal bimarkers in patients with Crohn's disease. Clin Gastroenterol Hepatol. 2008;6(11):1218-1224.

14. Mosli MH, Zou G, Garg SK, et al. C-reactive protein, fecal Calprotectin, and Stool Lactoferrin for Detection of endoscopic Activity in Syptomatic
Inflammatory Bowel Disease Patients: a Systematic Review and MetaAnalysis. Am J gastronterol. 2015;110(6):802-819.

15. Smith LA, Gaya DR. Utility of faecal calprotein analysis in adult inflammatory bowel disease. World J gastroenterol. 2012;18(46):67826789.

16. Fagerhol MK, Dale I, Andersson T. A radioimmunoassay for a granulocyte protein as a marker in studies on the turnover of such cells. Bull Eur Physiopathol respir. 1980;16 Suppl:273-282.

17. Konikoff MR, Denson LA. Role of faecal calprotectin as a biomarker of intestinal inflammation in inflammatory bowel disease. Inflamm Bowel Dis. 2006;12(6):524-534.

18. naismith GD, Smith LA, Barry SJ, et al. A prospective evaluation of the predictive value of faecal ca;protectin in quiescent Crohn's disease. $J$ Crohns Colitis. 2014;8(9):1022-1029.

19. Whitead SJ, French J, Brookes MJ, et al. Between- assay variability of faecal calprotectin enzyme- linked immunosorbent assay kits. Ann Clin Biochem. 2013;50(Pt 1):53-61.

20. Chang S, Malter L, Hudesman D. Disease monitoring in inflammatory bowel disease. World J of Gastrol. 2015;21(40):1146-1259.

21. Yacoub JH, Obara P, Oto A. Evolving role of MEI in Crohn's disease. $J$ Magn Reson Imaging. 2013;37(6):1277-1289.

22. Fiorino G, Bonifacio C, Peyrin- Biroulet L, et al. Prospective comperison of computed tomography esterography and magnetic resonance enterography for assessment of disease activity and complications in ileocolonic Crohn's disease. Inflamm Bowel Dis. 2011;17(5):1073-1080.

23. Van Assache G, Dignass A, Panes J, et al. The second europen evidensbased consensus on the diagnosis and management of Crohn's disease: definitions and diagnosis. J Crohns Colitis. 2010;4(1):7-27.

24. Lee SS, Kim AY, Yang SK, et al. Crohn Disease of the Small bowel: Comperison of CT enterography, MR Enterography, and SmallBowel Follow - Trough as Diagnostic Techniques 1. Radiology. 2009;251(3):751-761.

25. Sinha R, Verma $\mathrm{R}$, Verma $\mathrm{S}$, et al. MR enterography of Crohn disease: part 1, rational, technique, and pitfalls. AJR Am J Roentgenol. 2011;197(1):76-79.

26. Siddiki H, fidler J. MR imaging of the small bowel in Crohn's disease. Eur J radiol. 2009;69(3):409-417.

27. Jansen MD, Kjeldsen J, Rafaelsen SR, et al. Diagnostic accuracies of MR enterography and CT enterography in symptomatic Crohn's disease. Scand J Gastroentrol. 2011;46(12):1449-1457.

28. Desmond AN, O'Regan K, Curran C, et al. Crohn's disease: factors associated with exposure to high levels of diagnostic radiation. Gut. 2008;57(11):1524-1529.

29. Cipriano LE, Levesque BG, Zaric GS, et al. Cost- effectiveness of imaging strategies to reduce radiation-induced cancer risk in Crohn;s disease. Inflamm Bowel Dis. 2012;18(7):1240-1248.

30. Griffin N, Grant LA, Anderson S, et al. Small bowel MR enterography: problem solving in Crohn's disease. Insights Imaging. 2012;3(3):251-263.

31. Yoon K, Chang KT, Lee HJ. MRI for Crohn's disease: present and future. Biomed res Int. 2015;786-802.

32. Ordas I, Rimola J, Rodriguez S, et al. Accuracy of magnetic resonance enterography in assessing response to therapy and mucosal healing in patients with Crohn's disease. Gastroenterology. 2014;146(2):374-382.

33. Sipponen T, Nuutinen H, Turunen U, et al. Endoscopic evaluation of Crohn's disease activity: comparison of the CDEIS and the SES-CD. Inflamm Bowel Dis. 2010;16(12):2131-2136. 
34. Daperno M, D'Haens G, Van Assche G, et al. Development and validation of a new, simplified endoscopic activity score for Crohn;s disease: the SES-CD. Gastrointest Endosc. 2004;60(4):505-512.

35. Orzędała-Koszel U, Bachanek T, Karczmarek-Borowska B. Białko Creaktywne jako czynnik diagnostyczny w stanach zapalnych jamy ustnej i chorobach nowotworowych. Den Med Probl. 2005;42(1):131-136.

36. Hanriksen M, Jahnsen J, Lygren I, et al. C-reactive protein: a predictive factor and marker of inflammation in inflammatory bowel disease. Results from a prospective population- based study. Gut 2008;57(11):1518-1523.

37. Poulsen NA, Andersen V, Moller JC, et al. Comparative analysis of inflamed and non- inflamed colon biopsies reveales strong proteomic inflammation profile in patients with ulcerative colitis. $B M C$ gastroenterol. 2012;12:76.

38. D'Haens G, Ferrante M, Vermeire S, et al. Fecal calprotectin is a surrogate marker for endoscopic lesions in inflammatory bowel disease. Inflamm Bowel Dis. 2012;18(12):2218-2224.

39. Felvey JD, Hoskin T, Meijer B, et al. Disease activity assessment in IBD clinical indices and biomarkers fail to predict endoscopic remission. Inflamm Bowel Dis. 2015;21(4):824-831.

40. Roseth AG, Aadland E, Grzyb K. Normalization of faecal calprotectin a predictor of mucosal healing in patients with inflammatory bowel disease. Scand J Gastroenterol. 2004;39(10):1017-1020.

41. Sipponen T, Haapamaki J, Savilahti E, et al. Faecal calprotectin and S100A12 have low utility in prediction of small bowel Crohn's disease detected by wireless capsule endoscopy. Scand J Gastroenterol. 2012;47(7):778-784.

42. Gecse KB, Brandse JF, Van Wilpe S, et al. Impact of disease location on faecal calprotectin levels in Crohn's disease. Scan J Gastroenterol. 2015;50(7):841-847.
43. Schoepfer AM, Beglinger C, Straumann A, et al. Faecal calprotectin correlates more closely with the Simple Endoscopic score for Crohn's disease (SES-CD) than CRP, Blood leukocytes, and the CDAI. Am J gastroenterol. 2010;105(1):162-169.

44. Kiss LS, Szamosi T, Molnar T, et al. Early clinical remission and normalisation of CRP are the strongest predictors of efficacy, mucosal healing and dose escalation during the first year of adalimumab therapy in Crohn's disease. Aliment Pharmacol Ther. 2011;34(8):911-922.

45. af Bjorkesten CG, Nieminen U, Turunen U, et al. Surrogate markers and clinical indices, alone or combined, as indicators for endoscopic remission in anti-TNF- treated luminal Crohn's disease. Scand J Gastroenterol. 2012;47(5):528-537.

46. Delefortrie Q, Schatt P, Grimmelprez A, et al. Comparison of the Liaison calprotectin kit with a well established point of car test (Quantum BlueBuhlmann-Alere) in terms of analytical performances and ability to detect relapses amongst a Crohn population in follow-up. Clin Biochem. 2016;49(3):268-273.

47. Aryan A, Azizi Z, Teimouri A, et al. The diagnostic role of magnetic resonance enterography as a complementary test in active Crohn's disease. Middle East j Dig Dis. 2016;8(2):93-101.

48. Maccioni F, Ansari NA, Mazzamurro F, et al. Detection of Crohn disease lesions of the small and large bowel in pediatric patients: diagnostic value of MR enterography versus reference examinations. AJR Am J Roentgenol. 2014;203(5):W533-542.

49. D'Haens G, Ferrante M, Vermeire S, et al. Faecal calprotectin in a surrogate marker for endoscopic lesions in inflammatory bowel disease. Inflamm Bowel Dis. 2012;18(12):2218-2224.

50. Benitez JM, Garcia-Sanchez V. Faecal calprotectin: management in inflammatory bowel disease. World $J$ Gastrointest Pathophysiol. 2015;6(4):203-209. 